\title{
Reversal of Terminal Differentiation and Control of DNA Replication: Cyclin A and Cdk2 Specifically Localize at Subnuclear Sites of DNA Replication
}

\author{
M. Cristina Cardoso, Heinrich Leonhardt, \\ and Bernardo Nadal-Ginard \\ Howard Hughes Medical Institute \\ and Department of Cardiology \\ Children's Hospital \\ Boston, Massachusetts 02115 \\ Department of Cellular and Molecular Physiology \\ Harvard Medical School \\ Boston, Massachusetts 02115
}

\section{Summary}

DNA replication in mammalian celis occurs in discrete nuclear foci. Here we show that terminally differentiated myotubes can be induced to reenter $S$ phase and show the same pattern of replication foci as cycling cells. We used this cellular system to analyze the interaction of cell cycle proteins with these foci in vivo. Cyclin A and cdk2, but not cyclin B1 and cdc2, were specifically localized at nuclear replication foci, just like the replication protein proliferating cell nuclear antigen. A potential target of cyclin A and cdk2 is the 34 kd subunit of replication protein A (RPA34). In contrast with the $70 \mathrm{kd}$ subunit, which localizes to the foci, RPA34 was not detected at these replication sites, which may reflect a transient interaction. The specific localization of cyclin A and cdk2 at nuclear replication foci provides a direct link between cell cycle regulation and DNA replication.

\section{Introduction}

The ultimate target of the regulatory crossroads that control cell duplication in eukaryotic cells resides in the transition from $\mathrm{G} 1$ to $\mathrm{S}$ phase. One of the major roles of cell cycle regulation is to ensure that all DNA is replicated once and only once per cell cycle (for a review see Laskey et al., 1989). It has been estimated that the mammalian genome contains about 50,000 origins of DNA replication (Huberman and Riggs, 1968), all of which become active at specific times during $S$ phase (D'Andrea et al., 1983; Goldman et al., 1984; Hatton et al., 1988). However, the relative replication time of genes can change along with their transcriptional activity or chromosomal location (Dhar et al., 1989; Calza et al., 1984). Although the mechanism coordinating the activation of replication origins remains unknown, it is believed that the spatial and structural organization of the genome within the nucleus might play an important role in this regulation.

It has become increasingly clear that the mammalian nucleus is highly organized into foci or compartments, which spatially separate different biochemical processes like ribosome assembly (Kumar and Warner, 1972), DNA replication (Nakamura et al., 1986; Mills et al., 1989; Nakayasu and Berezney, 1989; van Dierendonck et al., 1989; Fox et al., 1991; O'Keeie et al., 1992), and RNA processing
(Wang et al., 1991; Huang and Spector, 1991; Carter et al., 1991; Spector et al., 1991; Xing et al., 1993; Carter et al., 1993). Different proteins participating in the same process are concentrated together in one functional compartment. DNA replication, for instance, occurs in discrete patterns of nuclear foci that undergo characteristic changes during $S$ phase. Moreover, replication-associated protein proliferating cell nuclear antigen (PCNA; Bravo et al., 1987; Prelich et al., 1987) was shown to be specifically localized at these DNA replication foci (Bravo and Macdonald-Bravo, 1987). Recently DNA methyltransferase, which acts postreplicatively, was also found at these foci (Leonhardt et al., 1992).

The signal transduction pathway(s) connecting regulators of cell cycle and DNA replication still remains unciear and controversial. Biochemical analysis is hampered by the overlapping substrate specificity of the cell cycleassociated kinases in vitro and does not take into account the limited spatial and temporal availability of most cyclins and cyclin-dependent kinases (cdks). On the other hand, transfection and microinjection experiments may lead to erroneous conclusions, owing to the addition of unphysiologically high protein concentrations, which may override feedback control mechanisms, for instance, by titrating other regulators. Moreover, studies using different organisms cannot be easily compared, since there are differences among phyla and even species. For instance, different cyclin-kinase combinations have been implicated in the G1/S phase transition in yeast (reviewed by Reed, 1991), Drosophila (Lehner et al., 1991), and Xenopus (Fang and Newport, 1991). Thus far, microinjection and transfection experiments, using rat and human cells, have demonstrated a requirement of cyclin D1 and cyclin E during progression through G1 (Baldin et al., 1993; Ohtsubo and Roberts, 1993) and of cyclin A and cdk2 for entry into $S$ phase (Girard et al., 1991; Pagano et al., 1992b; Zindy et al., 1992; Pagano et al., 1993; Tsai ot al., 1993).

One of the potential substrates for the cdc2 family of kinases, providing a link between these cell cycle factors and DNA replication, is RPA34, which is one of the three subunits of replication protein A, a single-stranded DNAbinding protein. Phosphorylation of RPA34 occurs at the onset of DNA replication (Din et al., 1990). As in most aspects of cell cycle regulation, several potential RPA kinases with similar biochemical properties have been identified. In vitro, phosphorylation of RPA34 could be accomplished by cdc2 kinase, containing either cyclin B or A (Dutta et al., 1991; Dutta and Stillman, 1992) as well as cdk2 immunoreactive complexes (Elledge et al., 1992). Physical association of cyclin A and cdc2 with replicating SV40 DNA in vitro was also reported (Fotedar and Roberts, 1991). The fact that multiple cyclin-kinase combinations can substitute for each other in these in vitro studies once more points to the limitations of the biochemical approaches in identifying physiologically meaningful interactions. In addition to RPA34, several other replication proteins are regulated at the posttranslational level, mostly 
by phosphorylation, and are possible targets of cell cycleassociated kinases. Finally, as yet, the potential regulatory role of the functional organization of the nucleus has been scarcely addressed.

Most studies on cell cycle regulation have been performed in cycling cells. An alternative approach is to analyze how terminally differentiated cells withdraw from the cell cycle and how they can be induced to reenter S phase. The expression of SV40 large T antigen in terminally differentiated myotubes (C2SVTts cells) was shown to induce DNA synthesis (Endo and Nadal-Ginard, 1989; Gu et al., 1993). Here we show that these induced myotubes can indeed undergo a program of DNA replication that in its characteristic patterns is indistinguishable from that of "normal" cycling cells. We analyzed the expression and subcellular distribution of proliferation-associated proteins by immunofluorescence microscopy. This approach allowed the analysis of individual nuclei and furnished information about the spatial and temporal interplay between cell cycle and DNA replication proteins. The specific localization of cyclin A and cdk2 at nuclear replication foci provided a direct link between cell cycle regulation and DNA replication. These results show how the functional organization of the nucleus can provide clues about protein function in vivo.

\section{Results}

Induction of Cellular DNA Replication by Large $T$ Antigen in Terminally Differentiated Myotubes

To study cell cycle regulation and DNA replication in myotubes, which are terminally differentiated and, therefore, permanently withdrawn from the cell cycle ("committed") and biochemically differentiated (Nadal-Ginard, 1978; Hastings and Emerson, 1984), might appear unorthodox. Differentiated multinucleated myotubes do not reenter the cell cycle or retrodifferentiate, not even in response to mitogen stimulation (Königsberg et al., 1960; Stockdale and Holtzer, 1961; Nadal-Ginard, 1978). No DNA synthesis could be measured in these differentiated myotubes, and cell cycle and DNA replication proteins were generally present only at a very low level, if at all (M. C. C., H. L., and B. N.-G., unpublished data).

DNA synthesis in myotubes can, however, be induced by expression of SV40 large $T$ antigen. The controlled expression of large $T$ antigen is possible in the C2SVTts cell line, which was derived from the mouse skeletal muscle cell line C2 (Yaffe and Saxel, 1977) by stable transfection with a thermosensitive SV40 large $T$ antigen mutant gene under the control of the inducible metallothionein I gene promoter (Endo and Nadal-Ginard, 1989). Expression of large $T$ antigen in C2SVTts myotubes was induced by addition of $\mathrm{Zn}^{2+}$ and shifting to the permissive temperature (from $39^{\circ} \mathrm{C}$ to $33^{\circ} \mathrm{C}$ ) and correlated with reinduction of DNA synthesis as visualized by bromodeoxyuridine (BrdU) incorporation in continuously labeled cultures (Figures $1 \mathrm{~A}$ and $1 B$ ). After 1 day, induction of large $T$ antigen had usually occurred in over $90 \%$ of myotube nuclei, though individual nuclei displayed different levels of protein. Pulse labeling with BrdU for 5 min prior to fixation further showed that DNA replication occurs in distinct nuclear compartments (Figure 1C), and the pattern of the DNA replication foci obtained in these induced myotubes was indistinguishable from the one observed in cycling cells (Nakamura et al., 1986). Moreover, DNA replication proteins like PCNA are also specifically localized at these nuclear DNA replication sites in myotubes (Figures $1 D$ and $1 E$ ) just as described for cycling cells (Bravo and MacDonald-Bravo, 1987, and references therein). The replication structures in these stimulated myotube nuclei were identical to those of cycling fibroblasts (see Figure 4B).

Progression through $S$ phase in this cellular system, though, does not require continuous presence of active large $T$ antigen, since a $6-8 \mathrm{hr}$ incubation in $\mathrm{Zn}^{2+}$. containing growth medium (GM) at $33^{\circ} \mathrm{C}$ followed by a shift to nonpermissive conditions (GM without $\mathrm{Zn}^{2+}$ at $39^{\circ} \mathrm{C}$ ) for 16-21 hr did not prevent induction of DNA synthesis (data not shown). Under these conditions, $T$ antigen is not expressed, and preexisting $T$ antigen molecules are inactive at this nonpermissive temperature (see Ray et al., 1992, and references therein). Together, these data show that myotube nuclei retain the potential to undergo a wellcoordinated round of cellular DNA replication. Large $T$ antigen seems to be required for the reversal of terminal differentiation but not for the progression through $S$ phase.

This immunofluorescence approach allows the analysis of individual cells, as well as comparison, side by side, of cycling myoblasts and myotubes before and after entering $S$ phase. This also avoids problems arising from mixed cell populations encountered by biochemical approaches. Moreover, it provides information about the subcellular localization and the spatial and temporal relationship to other proteins or biological processes.

\section{Specific Localization of Cyclin A and Cdk2 at Sites of Cellular DNA Replication throughout S Phase} The presence and activity of several cell cycle-associated kinases have been extensively correlated with the G1/S phase transition. As mentioned previously, it is, however, increasingly difficult to assign specific functions to particular cyclin-kinase complexes. For this reason, we analyzed the subcellular localization of various cell cycle proteins implicated in the control of DNA replication to gain some information about their possible role in vivo.

Terminally differentiated myotubes do not express cyclin A and have very low levels of cyclin A-associated cdk2 protein in their nuclei. In C2SVTts myotubes induced to reenter the cell cycle after large $T$ induction, cyclin A-associated kinase activity is restored (M. C. C., H. L., and $\mathrm{G}$. Condorelli, unpublished data). DNA replication in C2SVTts myotubes was induced by expression of large $T$ antigen, and the reinduction and localization of cyclin $A$ was analyzed. Indirect immunofluorescence staining with affinity-purified anti-cyclin A antibodies (Girard et al., 1991; these antibodies recognize a single molecular species of the expected $M_{r}$ in immunoblots of myoblast extracts [data not shown]) revealed several distinct patterns. In addition to the formerly described dispersed nuclear distribution with exclusion from the nucleoli (Girard et al., 1991; Pagano et al., 1992b; Pines and Hunter, 1991), we identified 

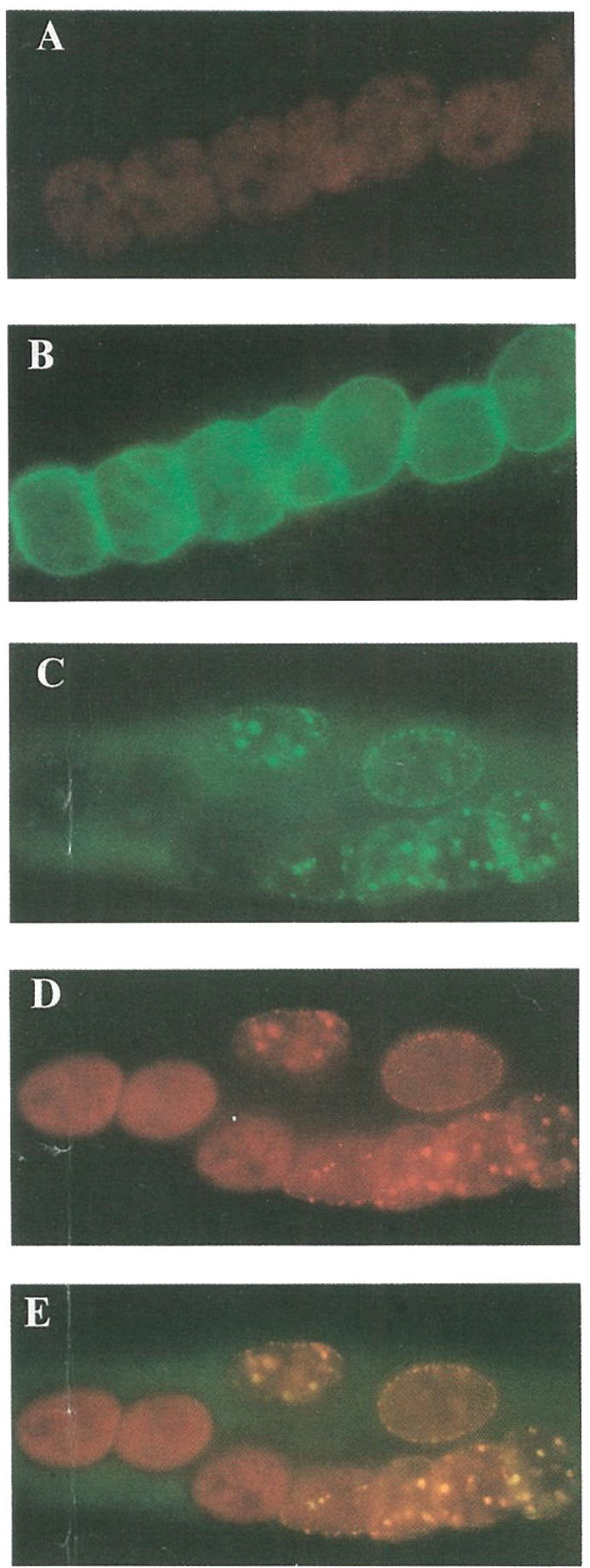

Figure 1. DNA Replication Structures in Myotubes upon T Antigen Expression

Induction of large $T$ antigen in differentiated C2SVTts myotube cultures was achieved by addition of $\mathrm{Zn}^{2+}$ and incubation at $33^{\circ} \mathrm{C}$ for 1 day in $\mathrm{GM}$.

(A and B) BrdU was added to the media throughout the induction period, and the cultures were fixed in formalin and sequentially immunostained for large $T$ antigen (A) with monoclonal antibody Pab101 (American Type Culture Collection; this antibody recognizes only large $T$ and not small t) and incorporated BrdU (B) with fluoresceinconjugated anti-BrdU monoclonal antibody (Boehringer Mannheim). The same field is shown to illustrate the correlation of the expression distinct patterns of punctate and ring-shaped structures (shown at high magnification in Figure 4A). This staining pattern was reminiscent of DNA replication patterns ( $\mathrm{Na}$ kamura et al., 1986; Nakayasu and Berezney, 1989; van Dierendonck et al., 1989; Fox et al., 1991; O'Keefe et al., 1992; see also Figures 1C-1E), raising the possibility that cyclin A might directly associate with sites of DNA replication, as described for the DNA replication protein PCNA (Bravo and Macdonald-Bravo, 1987) and, recently, for the murine DNA methyltransferase (Leonhardt et al., 1992). To test this hypothesis, cells were pulse labeled with BrdU immediately before fixation. The distribution of cyclin $A$ was analyzed by staining with anti-cyclin $A$ antibodies (Figure 2A). At least three different staining patterns could be distinguished in this field: a dispersed distribution, a very fine punctate pattern with numerous dots evenly distributed throughout the volume of the nucleus, and a pattern of a few large (about 1-3 $\mu \mathrm{m}$ ) ring- or loop-shaped structures. Subnuclear sites of ongoing DNA replication were visualized by costaining with BrdU-specific monoclonal antibodies (Figure 2B). Both staining patterns looked identical, and the superposition of both (Figure $2 \mathrm{C}$ ) indeed revealed their colocalization. The only exception was the nucleus showing a dispersed distribution of cyclin $A$. This nucleus showed no ongoing DNA replication as assayed by $\mathrm{BrdU}$ incorporation. To confirm the specificity of this immunofluorescence pattern further, we stained formaldehyde-fixed cells with two other polyclonal rabbit antisera raised against the entire human cyclin $A$ protein (Pines and Hunter, 1990; Pagano et al., 1992b). These antisera react with a single protein from mouse cell extracts whose pattern of expression and association with cdc2-related kinases is consistent with it being the murine cyclin $\mathrm{A}$ (Hamaguchi et al., 1992; data not shown). Significantly, colocalization of cyclin A with subnuclear sites of DNA replication was also observed with these two antisera (Figure 2D; data not shown), as well as with the previous one using different fixation methods (Figures $2 E$ and $2 F$ ), arguing all together against possible staining and fixation artifacts. Again, nuclei with a dispersed distribution of cyclin A did not show DNA replication (Figures $2 E$ and 2 F). To obtain additional evidence, we simultaneously stained methanolfixed cultures with anti-PCNA mouse monoclonal antibody and anti-cyclin $A$ rabbit polyclonal antibody. The ring- and dot-like pattern of cyclin A staining was coincident with the replication-associated PCNA pattern, and the same was true for the dispersed nucleoplasmic distribution in non-S phase nuclei (Figures 2G-21). The difference between cyclin $A$ and PCNA dispersed distributions resided

of large T with the induction of DNA synthesis. The BrdU-positive nuclei depict homogeneous staining due to the continuous labeling.

(C-E) BrdU was added to the media 5 min prior to methanol fixation, and the cells were sequentially stained for PCNA (D) with anti-PCNA monocional antibody Z049 (Zymed) and BrdU (C), as described above. (E) is a double exposure micrograph of the same field, showing the correspondence of DNA replication foci (visualized by BrdU label) and PCNA structures and the absence of DNA replication in the nuclei with dispersedly distributed PCNA. 

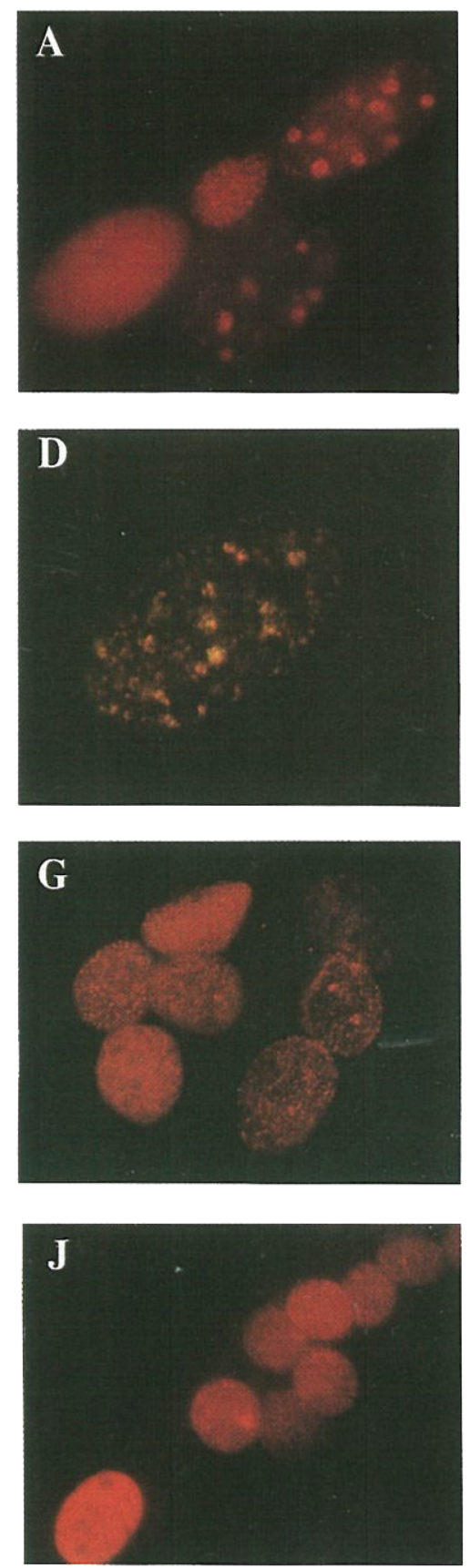
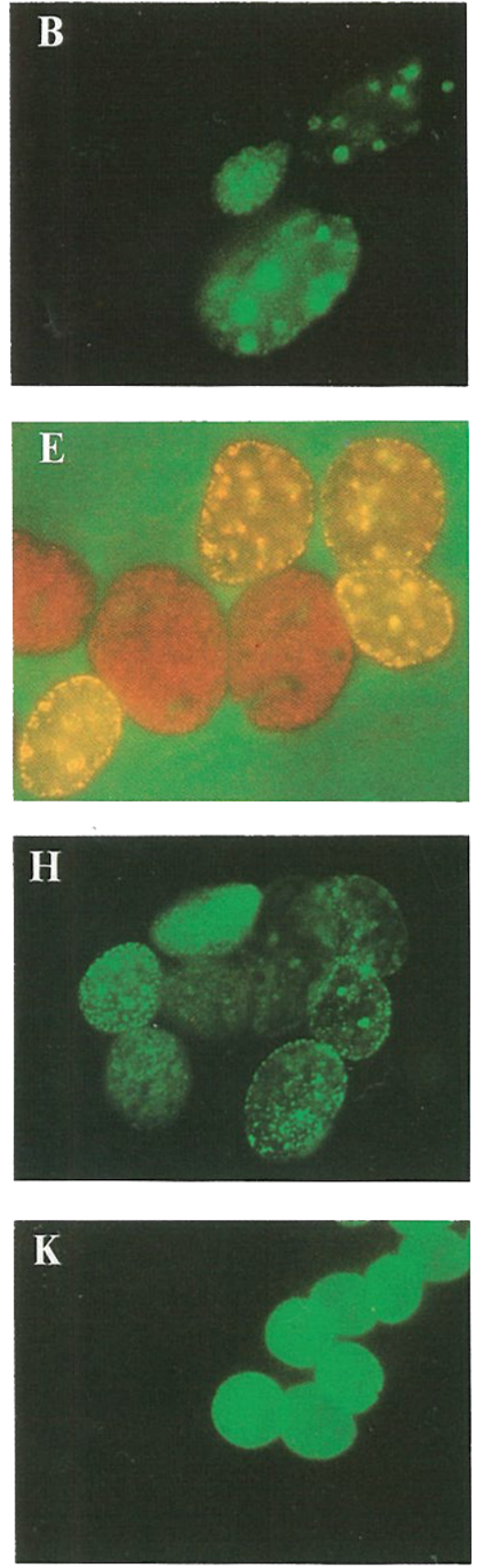
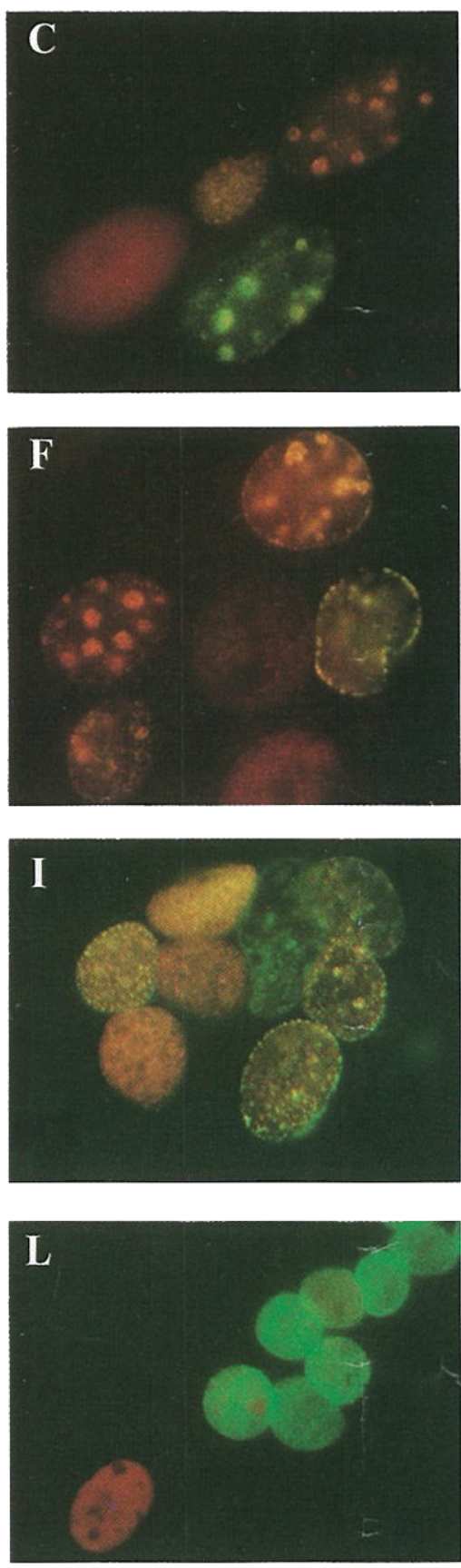

Figure 2. Cyclin A is Present at Sites of Nuclear DNA Replication

(A-C) C2SVTts myotubes incubated for 1 day in $T$ antigen-inducing conditions ( $G M$ plus $\mathrm{Zn}^{2+}$ at $33^{\circ} \mathrm{C}$ ) and pulse labeled with BrdU were permeabilized for $30 \mathrm{~s}$ with Triton X-100 and then formalin fixed and stained for cyclin A (red [A]) and BrdU (green [B]). A double exposure in (C) shows colocalization of cyclin A with sites of active DNA replication.

(D-F) The same results were obtained with a different anti-cyclin $A$ antibody (D) and with different fixation protocols (methanol fixation in [E] and formaldehyde fixation in [F]), all shown as double exposures.

(G-I) C2SVTts myotube cultures induced for 1 day were methanol fixed and simultaneously stained for cyclin A and PCNA. The same field is shown stained for cyclin A (red [G]) or PCNA (green [H]), with a double visualization of both in (I).

$(\mathrm{J}-\mathrm{L}) \mathrm{C} 2 \mathrm{SVTts}$ myotubes were induced as described above, except that BrdU was added continuously during the induction period, so any nuclei undergoing DNA replication at any time during the induction would be labeled, as opposed to the pulse labeling, which only allows detection of the ones actively replicating at the time between addition of the label and fixation. The same field is shown stained for cyclin A (red [J]), BrdU (green [K]), and cyclin A-BrdU (L). The homogeneous staining with BrdU is an effect of the continuous labeling. Note the nucleus that has not started replicating (BrdU-negative) and displays a dispersed distribution of cyclin $A$.

Cyclin A was detected with rabbit polyclonal antiserum (Pines and Hunter, 1990) in (D) and with affinity-purified rabbit antibodies (Girard et al., 1991) in the remaining stainings; PCNA, with an anti-PCNA mouse monoclonal Z049 (Zymed); BrdU, with fluorescein-conjugated anti-BrdU monoclonal antibody (Boehringer Mannheim). 

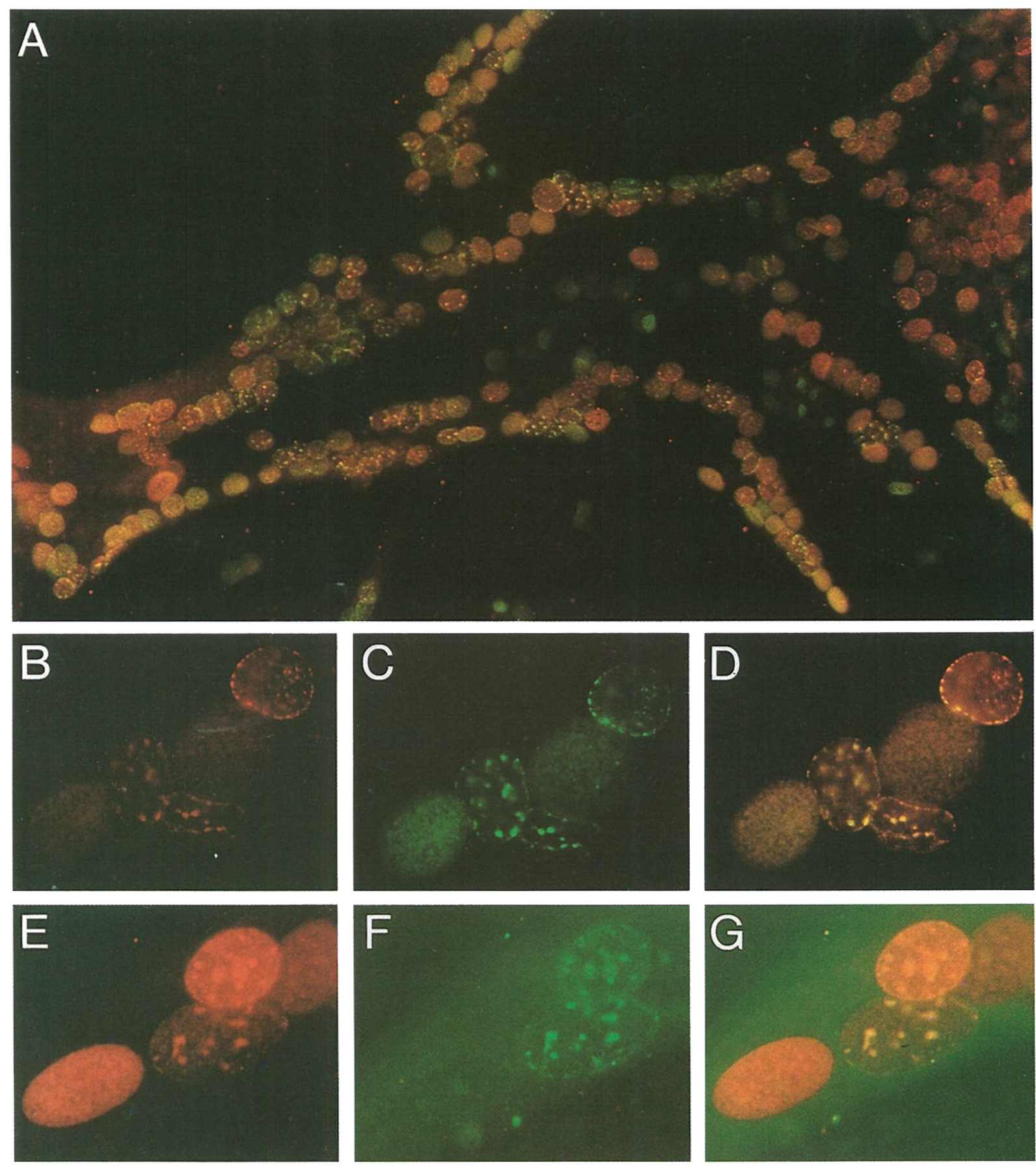

Figure 3. Colocalization of Cdk2 and Subnuciear DNA Replication Foci

C2SVTts myotubes were incubated for 1 day in $T$ antigen-inducing conditions (GM plus $\mathrm{Zn}^{2+}$ at $33^{\circ} \mathrm{C}$ ). BrdU was added to the media 5 min prior to methanol fixation, and the cultures were simultaneously stained for cdk2 and PCNA (A-D) or cdk2 and BrdU (E-G).

(A) Survey micrograph of a field stained for cdk2 (red) and PCNA (green), simultaneously visualized in this double exposure (as yellow-orange). (B-D) The same field at high magnification, stained for cdk2 (red [B]) or PCNA (green [C]), with a doubly exposed micrograph to show better the coincident staining of cdk2 and PCNA (D).

(E-G) The same field, also at high magnification, stained for cdk2 (red [E]), incorporated BrdU (green [F]), and a double exposure for cok2-BrdU (G). Notice that the nuclei showing dispersed cdk2 distribution are not replicating.

Cdk2 was detected with a rabbit antiserum generated against a nonconserved C-terminal peptide (Pagano et al., 1992b); PCNA with anti-PCNA mouse monocional antibody Z049 (Zymed); BrdU with anti-BrdU mouse monoclonal antibody (Amersham). 
in the fact that PCNA protein could be detected in virtually all the nuclei in the culture while cyclin A could be detected only in a subset and at variable levels. To determine whether this dispersed nucleoplasmic cyclin A staining could occur before $S$ phase, we continuously labeled cultures with BrdU and double stained the fixed cells for cyclin $A$ and BrdU. Figures $2 \mathrm{~J}-2 \mathrm{~L}$ show a nucleus in an induced myotube clearly containing cyclin $A$ that did not yet undergo DNA replication (note that the BrdU staining is homogeneous, owing to the continuous labeling procedure). These results indicate that the cyclin A dispersed nuclear staining can occur prior to DNA replication.

Cyclin $A$ is a regulatory subunit that associates with the serine/threonine protein kinases cdc2 and cdk2 to form active complexes that play key roles in cell cycle control. Current evidence implicates cyclin A-cdk2 kinase activity in the progression into $\mathrm{S}$ phase in mammalian cells (Tsai et al., 1991; Elledge et al., 1992; Rosenblatt et al., 1992; Pagano et al., 1992a, 1992b). Microinjection of cdk2specific antibodies into cultured human fibroblasts blocks entry into S phase (Pagano et al., 1993; Tsai et al., 1993). Furthermore, the mouse FT210 cell line, a temperaturesensitive cdc2 mutant, specifically arrests in G2 phase, indicating that the control of G1/S transition is not mediated by cdc2 (Hamaguchi et al., 1992). Consequently, we were interested in investigating the regulation of cdk2 protein in our system. Using a polyclonal rabbit anti-cdk2 antiserum raised against a nonconserved C-terminal peptide (Pagano et al., 1992b) with the double staining method outlined above, we studied the distribution of cdk2 in relation to PCNA in methanol-fixed C2SVTts induced myotubes. In extracts of these cells, this antiserum recognized a doublet of molecular mass about $34 \mathrm{kd}$ (data not shown). The simultaneous staining for cok2 and PCNA is shown at low magnification in a survey micrograph (Figure 3A). This field shows the high levels of cdk2 and PCNA in these induced nuclei, and it illustrates the perfect match between cdk2 and PCNA at replication foci. A higher magnification image presented in Figures 3B-3D allows better visualization of the striking recruitment of cdk2 to the same subnuclear structures to which PCNA redistributes throughout $S$ phase. Pulse labeling of these cultures with BrdU and costaining with cdk2-and BrdU-specific antibodies were performed as described earlier. The results shown in Figures 3E-3G also demonstrate the specific localization of cdk2 at sites of ongoing DNA replication and the absence of BrdU incorporation in the nucleus showing dispersed cdk2 staining, which agree with the above data on cyclin A. Similar results were obtained using a different polyclonal antiserum or simultaneously staining for cdk2 and cyclin A (data not shown).

The experiments described so far were performed with large $T$ antigen-expressing cells. To test whether the association of cdk2 and cyclin A with sites of DNA replication is independent of large T antigen, we double stained myogenic cells grown in conditions in which tsA58 mutant large $T$ is not active, as well as Swiss 3T3 fibroblasts. C2SVTts myotube cultures were induced for $8 \mathrm{hr}$ by changing to $\mathrm{Zn}^{2+}$-containing $\mathrm{GM}$ at $33^{\circ} \mathrm{C}$ followed by shifting to the nonpermissive conditions (GM without $\mathrm{Zn}^{2+}$ at $39^{\circ} \mathrm{C}$ ) for
$19 \mathrm{hr}$, as mentioned earlier. Using a different antiserum to cdk2, also raised against a nonconserved $\mathrm{C}$-terminal peptide (Tsai et al., 1993), we could see again coincident staining of cdk2 and BrdU structures (data not shown). Colocalization of cyclin A with sites of DNA replication was similarly observed in both mouse fibroblasts and cycling myoblasts grown in the absence of $\mathrm{Zn}^{2+}$ at $39^{\circ} \mathrm{C}$ (Figures $4 B$ and $4 C$; data not shown). The cyclin $A$ immunofluorescence staining pattern in fibroblasts and unfused myoblasts was, however, hardly visible with conventional microscopy. The cyclin A-containing structures were partially masked by dispersedly distributed cyclin $A$ and could only be detected by optical dissection with confocal laser microscopy, which might have made this pattern difficult to identify before. The reason for the clear visibility of the cyclin A and cdk2 structures in myotube nuclei is unknown. Induced myotubes represent a unique case of terminally differentiated skeletal muscie cells that were induced to

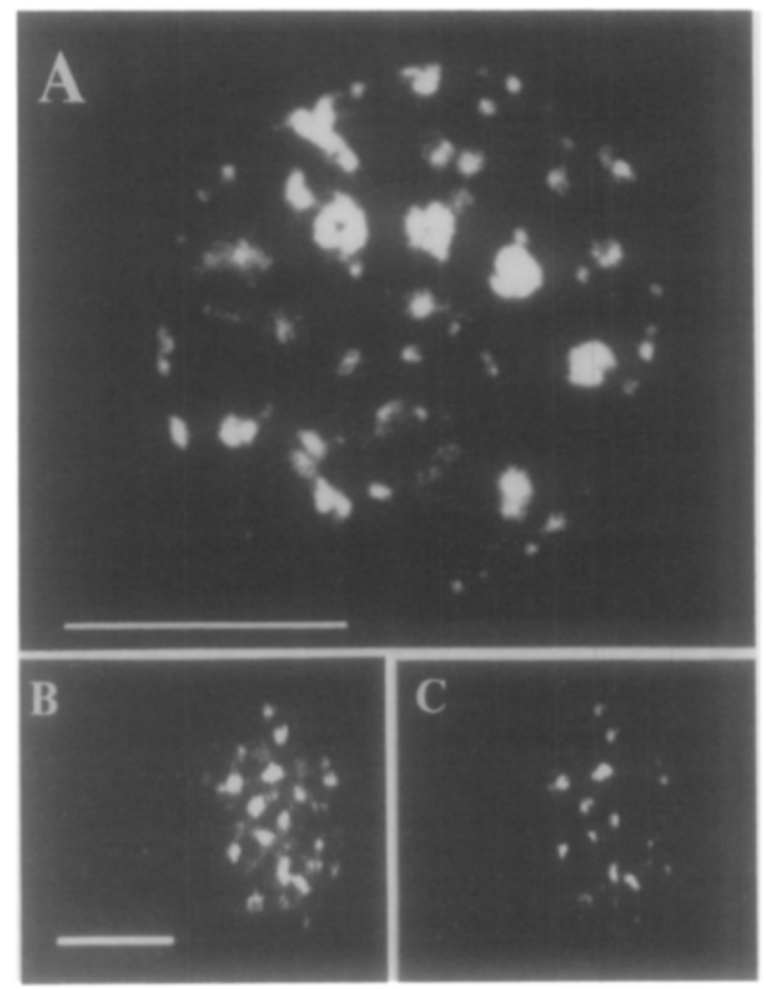

Figure 4. Visualization of Subnuclear Cyclin A-Containing Structures and Their Independence of the Presence of Large $T$ Antigen

(A) C2SVTts myotubes were incubated in $\mathrm{GM}$ plus $\mathrm{Zn}^{2+}$ at $33^{\circ} \mathrm{C}$ for 1 day before immunostaining with affinity-purified anti-cyclin $A$ rabbit antibodies and were analyzed by confocal laser scanning microscopy for a better visualization of the punctate and toroidal structures. (B and C) Swiss 3T3 fibroblasts were pulse labeled with BrdU, formaldehyde fixed, and costained for cyclin $A(C)$ and $B r d U(B)$. Replication patterns similar to the ones observed in the induced myotubes $(A)$ can be seen using confocal laser microscopy in these mouse fibroblasts, which are devoid of large $\mathrm{T}$ antigen.

Cyclin A was detected with affinity-purified rabbit antibodies (Girard et al., 1991), and BrdU was detected with fluorescein-conjugated antiBrdU monoclonal antibody (Boehringer Mannheim). Optical sections were obtained using the Bio-Rad MRC-600 confocal imaging system. Bar, $10 \mu \mathrm{m}$. 

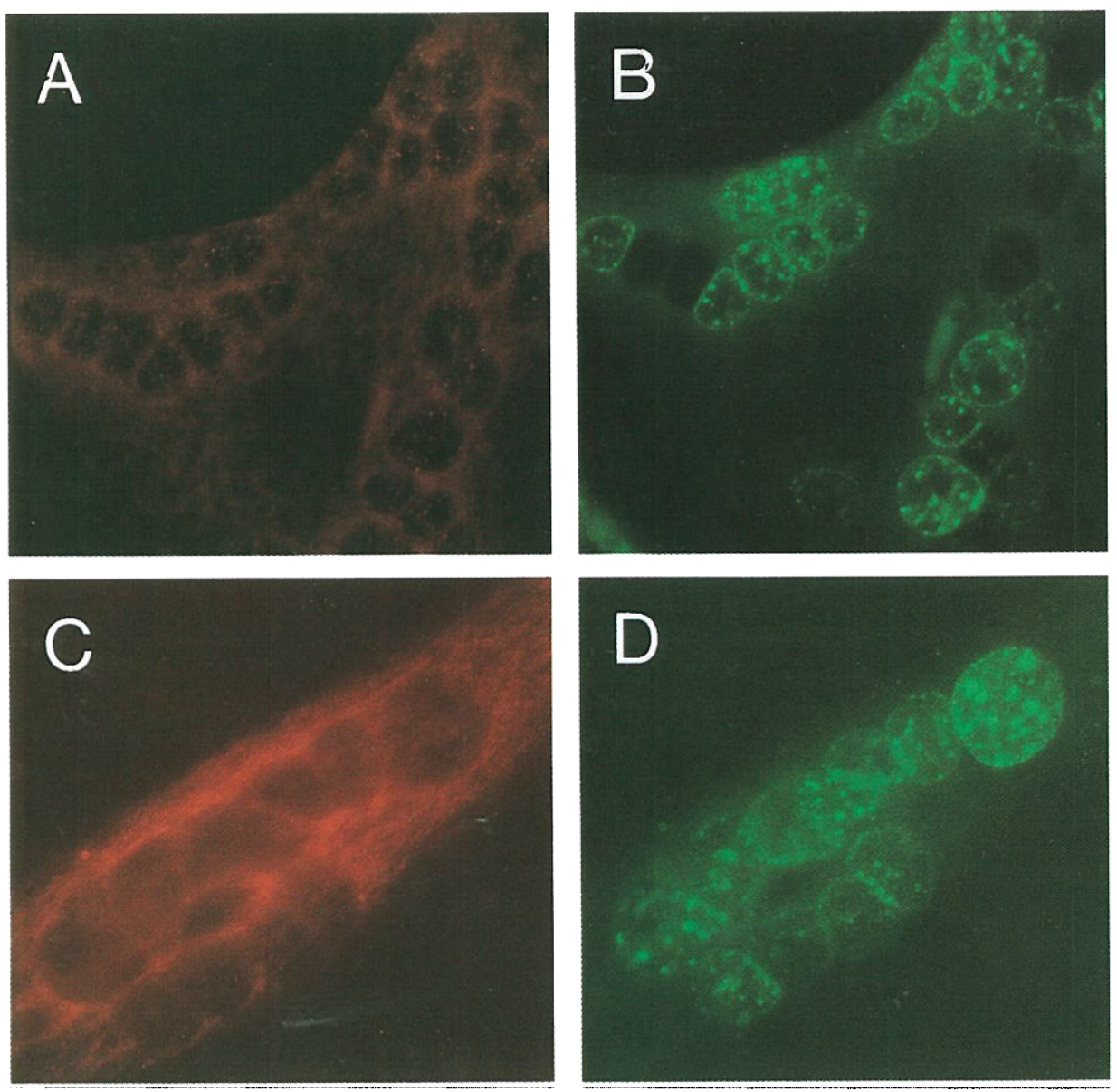

Figure $5{ }^{b}$ Cyclin B1 and Cdc2 Are Not Present at Sites of Active DNA Synthesis

(A and B) C2SVTts myotubes were incubated for 1 day in T antigen-inducing conditions (GM plus $\mathrm{Zn}^{2+}$ at $33^{\circ} \mathrm{C}$ ). $\mathrm{BrdU}$ was added to the media 5 min prior to formalin fixation. Cells were sequentially stained for cyclin B1 (red [A]) with an anti-cyclin B1 antiserum (Pines and Hunter, 1989) and for BrdU (green [B]) with fluorescein-conjugated anti-BrdU monoclonal antibody (Boehringer Mannheim).

(C and D) C2SVTts myotubes treated as described above were methanol fixed and sequentially stained for cdc2 (red [C]) with affinity-purified rabbit antibody to C-terminal peptide (Oncogene Science) as above and for BrdU (green [D]) with fluorescein-conjugated anti-BrdU monoclonal antibody (Boehringer Mannheim). Neither cyclin B1 nor cdc2 could be detected at DNA replication foci.

reenter $S$ phase and might simply have lower levels of dispersed cyclin A and cdk2 in their nuclei.

\section{Absence of Cyclln B1 and Cdc2 from DNA Replication Foci}

The results presented so far suggest adirect role of cyclin $A$ and cdk2 in DNA replication throughout $S$ phase in vivo. In contrast, cyclin B-cdc2 complexes in mammalian cells have been extensively studied and shown to play a role in G2/M transition. Recently, however, cyclin B-cdc2 was reported as the major RPA34 kinase, which is required for the initiation of DNA replication in vitro (Dutta and Stillman, 1992). Therefore, we investigated the localization of cyclin B1 using a polyclonal rabbit anti-human cyclin B1 antiserum (Pines and Hunter, 1989). This antiserum was raised against the human protein, but it also recognizes mouse cyclin B (Hamaguchi et al., 1992). We were unable to detect any cyclin B1 at active sites of DNA replication, assayed by BrdU incorporation of pulse labeled cultures using either induced C2SVTts myotubes (Figures 5A and $5 \mathrm{~B}$ ) or asynchronously growing $\mathrm{C} 2$ myoblasts, which had no detectable cyclin B1 nuclear staining during $S$ phase and showed nuclear staining only in some non-S phase cells (data not shown). These results are in agreement with previous studies localizing cyclin B predominantly in the cytoplasm until just before mitosis (Pines and Hunter, 1991; Gallant and Nigg, 1992). During myogenic differentiation p34 ${ }^{\text {cdc2 }}$-associated kinase activity and protein level decrease rapidly and are reinstated between 6 and $12 \mathrm{hr}$ after $\mathrm{T}$ antigen expression ( $\mathrm{Gu}$ et al., 1993; data not shown). We used an affinity-purified rabbit anti-peptide antibody to cdc2 to investigate the localization of this protein in S phase myotube nuclei. We could not detect cdc2 protein in nuclei undergoing DNA replication as visualized by BrdU labeling (Figures $5 \mathrm{C}$ and $5 \mathrm{D}$ ) or by PCNA staining, and the same was observed in asynchronously growing C2 myoblasts (data not shown). Altogether, the actual levels of cyclin B1 and cdc2 are difficult to determine, since the cytoplasm of myotubes gave relatively high background staining, but clearly neither cyclin B1 nor cdc2 protein was detected at nuclear replication foci with any of these antibodies, both in myotubes and myoblasts. 

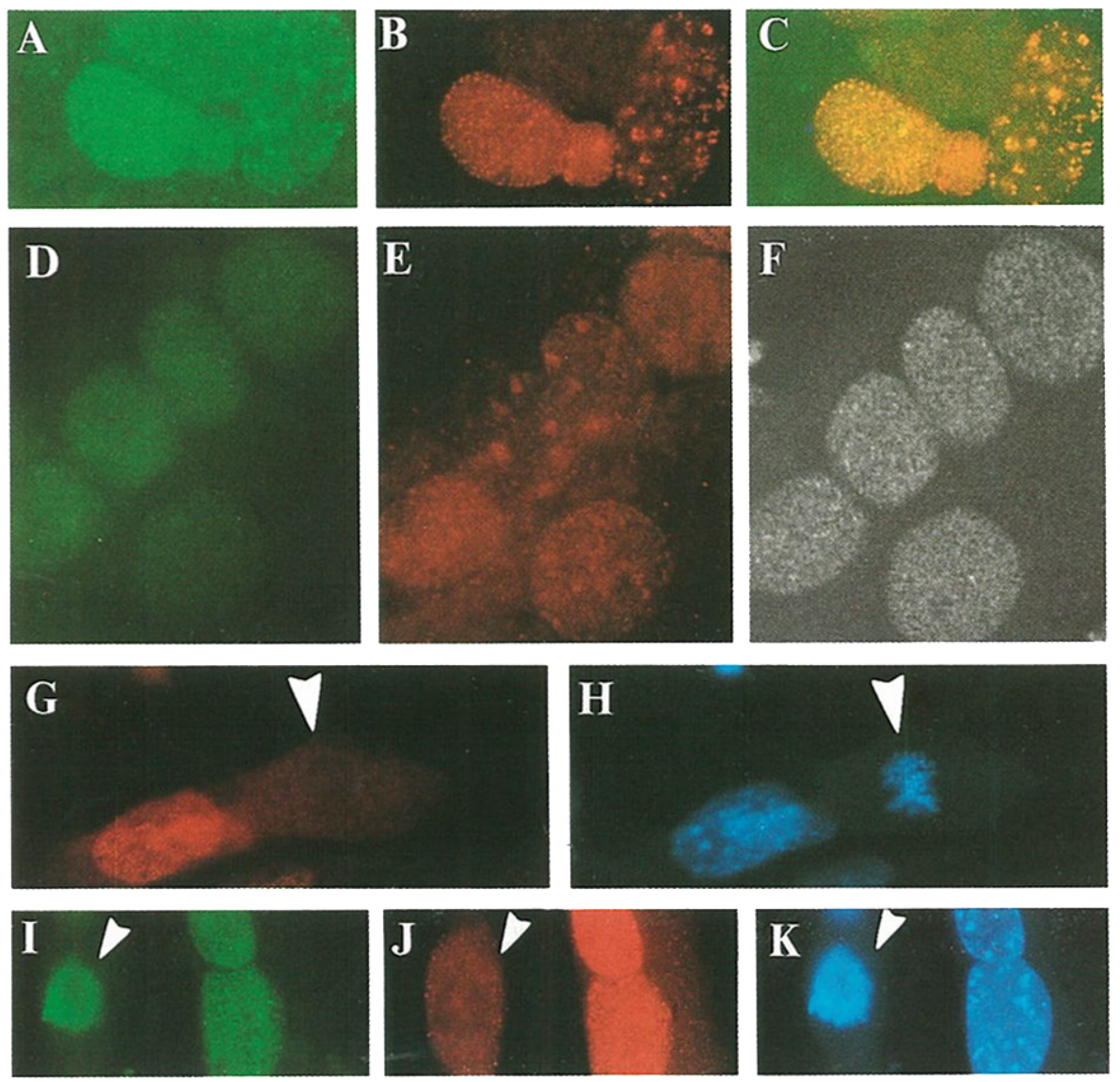

Figure 6. Differential Distribution of RPA34 and RPA70

C2SVTts myotube cultures were incubated for 1 day at $33^{\circ} \mathrm{C}$ in GM plus $\mathrm{Zn}^{2+}$, formalin fixed, immunostained, and counterstained for cellular DNA with Hoechst 33258 . Mitotic figures are marked by arrowheads.

(A-C) One field costained for RPA70 (green [A]) with monoclonal antibody aRPA70B (Kenny et al., 1990) and cyclin A (red [B]) with affinity-purified rabbit anti-cyclin A antibodies (Girard et al., 1991). (C) is a double exposure to evaluate better the colocalization of cyclin A and RPA70 structures. (D-F) The same field viewed by conventional and confocal microscopy ([D] and [E], conventional; [F], confocal), showing RPA34 (D and F), detected by monoclonal antibody aRPA34A (Kenny et al., 1990), and cyclin A (E), detected as described above.

$(G$ and $H)$ One field showing the absence of RPA70 (red [G]) from the mitotic chromosomes (blue $[H]$ ), detected as above.

(I-K) One field showing RPA34 distribution (green [I]) and cdk2 (red [J]) staining using a C-terminal rabbit anti-peptide antiserum (Pagano el al., $1992 b$ ) and counterstained with Hoechst 33258 (blue [K]). RPA34 is associated with the condensed chromosomes in M phase, while cdk2 is not.

\section{Distribution of Replication Protein A Subunits}

One of the potential targets of cdks at replication foci is RPA34. Replication protein A is required for DNA replication, and phosphorylation of RPA34 was proposed to be a key regulatory event controlling the onset of DNA replication (Din et al., 1990). Addition of either clam cyclin A or sea urchin cyclin $B$ to a human mid-G1 cell extract stimulated its ability to support SV40 DNA replication (D'Urso et al., 1990). In other words, there is a requirement for a cdc-like kinase activity at the transition to S phase, and phosphorylation of RPA34 is known to correlate with the onset of DNA replication. We, therefore, analyzed the distribution of RPA34 and also RPA70, using the monoclonal antipodies $\alpha$ RPA70A, $\alpha$ RPA $70 B$, and $\alpha$ RPA $70 C$ to the 70 kd subunit (single-stranded DNA-binding protein, RPA70) and one monoclonal antibody, $\alpha$ RPA34A, to the $34 \mathrm{kd}$ subunit (RPA34) (Kenny et al., 1990). Induced C2SVTts myotubes were simultaneously stained for either of the two subunits, together with cyclin A-or cdk2-specific anti- bodies. Figures $6 \mathrm{~A}-6 \mathrm{C}$ show colocalization of RPA70 and cyclin A at ring- and dot-shaped DNA replication structures. Colocalization of RPA70 and cdk2 at replication foci - was also observed with different antibody combinations and fixation procedures (data not shown). These results are in partial agreement with studies using a Xenopus cell-free replication system, where RPA70 was found to associate with pre- and early DNA replication foci (Adachi and Laemmli, 1992). In contrast, we were not able to visualize any specific concentration of RPA34 at DNA replication structures by double staining either with cdk2-specific antibodies (Figures $6 \mathrm{I}$ and $6 \mathrm{~J}$ ) or with cyclin A-specific antibodies, using various fixation and staining protocols (Figures $6 \mathrm{D}$ and $6 \mathrm{E}$ ). This result was also confirmed by obtaining optical sections through the nuclei with a confocal laser scanning microscope, which clearly displays a dispersed distribution of RPA34 during $S$ phase (Figure $6 F$ shows the same field as Figures $6 D$ and $6 E$ ). Further analyses of the cellular distribution of these proteins 
showed exclusion of RPA70 and cyclin A from condensed chromosomes in $\mathrm{M}$ phase (Figures $6 \mathrm{G}$ and $6 \mathrm{H}$; data not shown). In contrast, RPA34 appeared to be associated with condensed chromosomes, while cdk2 was excluded (Figures 6l-6K).

The colocalization with Hoechst-stained DNA described in Figure 6 cannot be due to unspecific association with DNA in general. The colocalization of cyclin A, cdk2, and RPA70 on one hand and RPA34 on the other hand is, first of all, very different and, second, changes along the cell cycle. The bright Hoechst-stained spots mostly represent concentrations of heterochromatin (Weisblum and Haenssler, 1974; Moser et al., 1975), which are known to be replicated late in S phase, and that is when enzymes involved in DNA replication, including RPA70, cyclin A, and cdk2, colocalize with these structures as was described for DNA methyltransierase (Leonhardt et al., 1992). We did not observe colocalization at other phases of the cell cycle, which clearly argues against unspecific association with DNA. However, RPA34, but not RPA70, cyclin A, and cdk2, associates with DNA during $M$ phase but not during $S$ phase (Figure 6). This is only one example to show the very different distribution of RPA34 and cdk2-cyclin A and their cell cycle-dependent redistribution, which clearly rules out any optical spillover, antibody cross-reactivity, or unspecific association with DNA. The very different distribution of the two subunits of replication protein $A$ is quite surprising, and possible explanations are discussed below.

\section{Discussion}

\section{Induction of DNA Replication in Myotubes}

Terminally differentiated skeletal muscle cells are permanently withdrawn from the cell cycle and do not initiate DNA replication upon growth factor stimulation (Kónigsberg et al., 1960; Stockdale and Holtzer, 1961; NadalGinard, 1978). We show that expression of SV40 large T antigen causes terminally differentiated myotube nuclei to reenter an authentic $S$ phase. The patterns of DNA replication foci observed in these induced myotube nuclei (Figures 1-4) are in fact indistinguishable from those of cycling myoblasts and fibroblasts (Figure 4). These patterns are known to change along with $S$ phase progression in a characteristic way (Nakamura et al., 1986; Mills et al., 1989; Nakayasu and Berezney, 1989; van Dierendonck et al., 1989; Fox et al., 1991; O'Keefe et al., 1992). This program of stage-specific DNA replication patterns is the result of the spatial organization and redistribution of the genome and the activation of each of the estimated 50,000 origins of DNA replication at specific times during $S$ phase. The visualization of typical early, mid, and late $S$ phase replication patterns (compare Figures 1-4 with above references) indicates that myotubes retain the potentiality to undergo a complete and well-coordinated S phase, which can be unlocked simply by expression of the viral SV40 $T$ antigen. Yet, continuous expression of large $T$ was not required, suggesting a role in overriding a block and/or passing a restriction point but not in actually driving DNA replication, as in the viral infection. Large $T$ antigen acts, at least in part, through the inactivation and deinduction of the retinoblastoma protein (Gu et al., 1993; M. C. C., H. L., and B. N.-G., unpublished data) and other related proteins (J. W. Schneider and B. N.-G., unpublished data). These results, furthermore, support a view of terminal differentiation as a product of active and continuous regulation (Blau, 1992; Gu et al., 1993) rather than an irreversible default state. It will be interesting to see whether other terminally differentiated cells can also be induced to reenter cell cycle.

\section{Asynchronous S Phase in Neighboring Myotube Nuclei}

The visualization of DNA replication in myotubes also revealed a surprising degree of asynchrony. Nuclei within the same myotube, sharing the same cytoplasm and separated by only a few micrometers, can show very different DNA replication patterns. Figures 2A-2F, for instance, show nuclei with a typical early replication pattern right next to nuclei with a typical mid to late $S$ phase pattern and nuclei with no DNA replication at all. This asynchrony cannot be easily explained by different expression rates of large $T$ antigen and/or genes induced by it, since all nuclei share the same cytoplasm and any protein should be equally available to all of them, unless the cytoplasm is organized into domains, functionally separating neighboring nuclei. An extreme interpretation of the concept of nuclear domains in muscle fibers (reviewed by Hall and Ralston, 1989) could explain this heterogeneity among myotube nuclei in a way such that the mRNA would remain preferentially associated with the nucleus and/or the translation products would be selectively "guided" back to the nucleus the mRNA came from. Such a "homing behavior" of nuclear proteins would impose serious limitations on experimental or therapeutic approaches using heterokaryons.

The timing for entry into $S$ phase might also be dictated by the nucleus itself, explaining the observed asynchrony of DNA replication in myotube nuclei. Results in support of this interpretation were obtained in a Xenopus cell-free DNA replication system. Artificial nuclei, spontaneously assembled in Xenopus egg extracts, entered $S$ phase at different times, even though they shared the same "cytoplasm" (Blow and Watson, 1987), while demembranated nuclei enclosed within the same nuclear membrane entered S phase at the same time (Leno and Laskey, 1991). These results from this in vitro replication system suggested that the nuclear membrane determines the timing of DNA replication. Induced C2SVTts myotubes represent a unique system to study the regulatory role of the nucleus and the nuclear membrane in vivo. Possible roles of the nuclear membrane are discussed below.

\section{The Order in the Nucleus and the Link between DNA Replication and Cell Cycle Regulation}

Our understanding of cell cycle regulation is challenged by the continued discovery of new cyclins, cdks, and other regulatory proteins, which often have similar biochemical properties and overlapping substrate specificities in vitro. It becomes increasingly difficult, if not impossible, to as- 
sign specific cyclin-cdk complexes to cell cycle phosphorylation events. The present analysis focused on the transition to $S$ phase and the initiation of DNA replication.

Biochemical analyses have shown that the phosphorylation of RPA34 is a key event at the initiation of DNA replication (Din et al., 1990) that can be performed in vitro by cyclin A, cyclin B, cdc2, and cdk2 (Fotedar and Roberts, 1991; Dutta and Stillman, 1992; Elledge et al., 1992). Here we show that cyclin $B$ and cdc2 are not present in the nucleus during $S$ phase (Figure 5 ), which is consistent with previous studies (Pines and Hunter, 1991), arguing altogether against their involvement in the control of DNA replication. In contrast, cyclin A and cdk2 are induced after reversal of terminal differentiation and are specifically localized at subnuclear sites of ongoing DNA replication in vivo. Colocalization was observed with DNA replication patterns typical of early, mid, and late $S$ phase, suggesting that cyclin $A$ and cdk2 act throughout $S$ phase and not only at the beginning. This cell cycle-dependent redistribution of cyclin $A$ and cdk2, which perfectly matches that of replication protein PCNA (Figures 2 and 3), strongly suggests a direct role of these proteins in the control of DNA replication. This specific localization of cell cycle proteins at DNA replication foci could represent the long sought after link between cell cycle regulation and DNA replication. The demonstration of colocalization by itself does not prove their involvement, but it forms a consistent picture, together with biochemical data showing that cyclin A and cdk2 can phosphorylate RPA34 and that phosphorylation of RPA34 occurs at the initiation of DNA replication. The specific localization of cyclin $A$ and cdk2 at replication foci also fits with the observation that only RPA34 bound to DNA in the initiation complex is a substrate for phosphorylation (Fotedar and Roberts, 1992). At this moment we cannot rule out that cyclin $A$ and cdk2 might, in addition or alternatively, phosphorylate other proteins present at DNA replication foci. Moreover, this observation does not necessarily preclude their having additional roles, e.g., in transcription complexes involving E2F, as suggested by others (reviewed by Nevins, 1992).

Given the complexity of changes during G1 and S phase, we focused this analysis on potential RPA34 kinases and, at the same time, proteins shown to be required at the onset of $S$ phase. However, it would not be surprising to find other cell cycle proteins at the replication foci. Cyclin $E$ (isolated from human cells) and cyclin D (several different members were isolated from mouse and human sources) are thought to be required for $\mathrm{G} 1$ phase progression (reviewed by Lew and Reed, 1992). In initial experiments, however, no specific localization of cyclin E at DNA replication foci could be detected in MRC- 5 or HeLa cells (M. C. C. and E. Lees, unpublished data). Cyclin E level was recently shown to be rate limiting for $\mathrm{G} 1$ progression (Ohtsubo and Roberts, 1993), and it might also be necessary during $S$ phase but, according to our preliminary data, not directly at the replication centers. Other potential candidates are currently being screened.

These results contribute to a picture depicting the nucleus as a highly organized entity, where processes like transcription, RNA processing, and DNA replication take place in distinct nuclear foci. Here we show that this functional compartmentalization of the nucleus can provide valuable clues about the role of nuclear proteins in vivo. The organization of the nucleus is most likely achieved by a web of protein-protein interactions assembling functionally active complexes. There is also evidence that DNA replication complexes are associated with the nuclear matrix as well as with chromosomes (for a review see Cook, 1991). This complexity clearly defies traditional biochemical analyses, in the sense that proteins that interact in vitro may be separated into two different nuclear compartments in vivo. This may also explain how cyclin-cdk kinases may show overlapping substrate specificity in vitro and still precisely carry out specific tasks in vivo that are probably not redundant. It is tempting to speculate that cyclins control the activity of their dependent kinases by allosteric activation as well as targeting to reactive centers like the subnuclear replication foci. In addition, proteins with weak interactions and low catalytic rate may be effectively concentrated in reactive centers and simultaneously forced into a more active conformation. The specific concentration of proteins involved in the different steps of DNA duplication at the replication site, in an assembly line type of arrangement, creates a microenvironment where the efficiency of the overall process is greatly enhanced. This would explain why it has not yet been possible to establish an efficient in vitro mammalian DNA replication system. Finally, many important in vivo interactions will escape detection by coimmunoprecipitation studies if they are part of an insoluble complex with the nuclear matrix and/or the chromosomes, like DNA replication complexes. These problems could be partially solved by a detailed analysis of the cellular localization of proteins at different stages of the cell cycle. The cellular system described here seems to be particularly convenient for this type of analysis.

\section{The License to Replicate}

The precise regulation allowing each of the estimated 50,000 origins of mammalian cells to be used only once during $\mathrm{S}$ phase is a prerequisite for the stable maintenance of the genome and the genetic information. Early cell fusion experiments indicated that $S$ phase cells contain factor(s) that can promote G1, but not G2, nuclei to enter S phase (Rao and Johnson, 1970). Biochemical analyses showed that $\mathrm{S}$ phase cells contain a cdk that is required for DNA replication (Roberts and D'Urso, 1988; D'Urso et al., 1990). In this communication we show that cyclin $A$ and cdk2 are specifically localized at DNA replication foci just like replication protein PCNA (Figures 2 and 3), suggesting that the "S phase-promoting factor," alias "replication factor $S$," should be a cyclin A-cdk2 complex. Cdk2 protein is present throughout the cell cycle (Rosenblatt et al., 1992; Pagano et al., 1992a, 1992b), whereas cyclin $A$ is induced in late G1/early $S$ phase and is degraded in $M$ phase (Pines and Hunter, 1990). This, however, cannot explain why G2 nuclei are refractory to this stimulation, both in fusion experiments (Rao and Johnson, 1970) and in normal cells, which contain high levels of cyclin $A$ and cdk2. To investigate this problem, we analyzed the cellular 


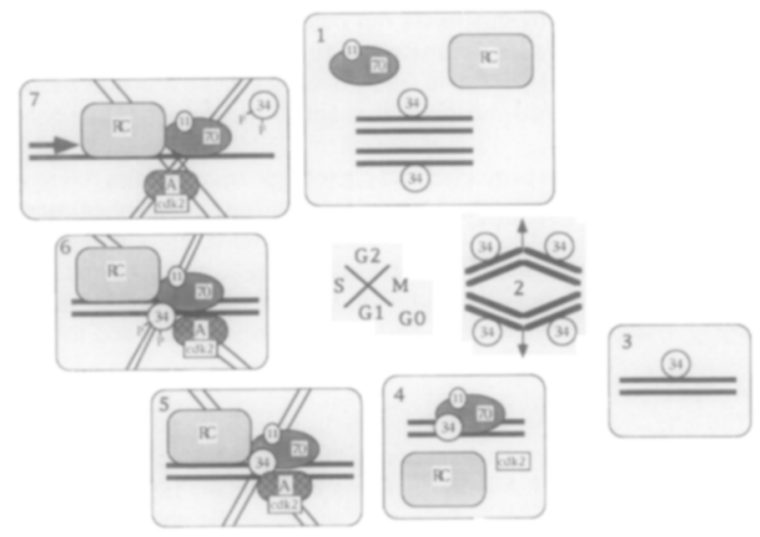

Figure 7. A Model for the Regulation of DNA Replication

This model attempts to outline a possible role of cyclin A-cdk2 and RPA34 in the regulation of DNA replication and by no means claims completeness (see Discussion). The observation that DNA replication seems to occur at the nuclear matrix in replication foci is represented by crossed double lines underlying the complex. Proteins depicted are replication protein $A$ with its 70,34 , and 11 kd subunits; cyclin $A$ (A); and cdk2. DNA is represented by thick lines, and RC comprises all other known and unknown proteins required for DNA replication. (1) Unphosphorylated form of RPA34 in the nucleus binds to DNA at the end of G2/early $M$ phase and stays bound until S phase. (2) During nuclear envelope breakdown at mitosis, unbound RPA34 is degraded and/or excluded trom the nucleus. (3) Bound RPA34 remains in the nucleus during quiescence (or terminal differentiation), while other replication and cell cycle factors are down-regulated. (4-5) During G1, replication complexes assemble around the bound RPA34. (5-6) At the onset of S phase, cyclin A-cdk2 complexes at the replication sites phosphorylate RPA34 and trigger initiation of DNA replication. (7) Phosphorylated RPA34 is released from replication complexes during elongation and remains unbound in the nucleoplasm till the end of $\mathrm{G} 2$, when it is dephosphorylated and can again bind to DNA, marking it for the next round of replication.

distribution of RPA34, the potential target of cyclin A and cdk2 and necessary for DNA replication in vitro (Kenny et al., 1990; Erdile et al., 1990). Immunofluorescence analysis showed colocalization of RPA70, but not RPA34, with cyclin A or cdk2 at DNA replication foci (Figure 6). The monoclonal antibody used for detection of RPA34 was raised against human RPA (Kenny et al., 1990) and recognizes the mouse homolog as a doublet band of around 30-34 kd on Western blots (presumably corresponding to the phosphorylated and unphosphorylated forms as described by Din et al., 1990; data not shown) as well as by immunofluorescence microscopy (Figure 6), but we cannot completely rule out a loss of the epitope due to conformational changes and/or masking at the replication foci. A more likely and interesting interpretation of these results is that RPA34 is released from the initiation complex upon phosphorylation, while RPA70 stays on, acting as singlestranded DNA-binding protein and stimulating DNA replication. This proposal might seem improbable in view of the high stability of the isolated RPA complex in vitro, but, on the other hand, RPA70 and RPA11, but not RPA34, were detected in recombination complexes (Moore et al., 1991). Moreover, all three subunits are required for the process of SV40 replication, but RPA70 alone can stimulate DNA polymerase $\alpha$ (Erdile et al., 1991).
Further analysis showed that RPA34, but not RPA70, is associated with condensed chromosomes in $M$ phase (Figure 6). The association of RPA34 with chromosomal DNA may start at late G2 and may last until S phase (detailed analysis in progress). The direct or indirect binding of RPA34 to chromosomal DNA is surprising but actually consistent with the fact that the mouse RPA34 was fortuitously isolated and cloned as a DNA-binding protein ( $\mathrm{Na}$ kagawa et al., 1991). These features of RPA34 are reminiscent of the licensing factor postulated by Blow and Laskey (1988).

We would like to propose the following model (Figure 7), which is obviously oversimplified but tries to account for the data presented so far. The unphosphorylated form of RPA34 binds to DNA during G2 phase, remains bound until $S$ phase, and marks DNA for replication. Unbound RPA34 is degraded and/or excluded from the nucleus upon formation of the nuclear membrane. In late G1, initiation or prereplication complexes are assembled around the bound RPA34, which are then activated in $S$ phase by the cyclin A-cdk2 complexes at the replication sites. Phosphorylation causes the release of RPA34 and triggers DNA replication. The phosphorylated form of RPA34 cannot bind to DNA, which ensures that the released RPA34 cannot cause a second activation of DNA replication origins. In late G2 phase, RPA34 is dephosphorylated and binds to DNA again. This model would explain the classical observations by Rao and Johnson (1970): G1 nuclei are licensed to replicate, they have DNA marked by RPA34 and might also have prereplication complexes assembled, and they can be promoted to enter $S$ phase by fusion with $S$ phase nuclei, which provide the activator cyclin A-cdk2. G2 nuclei are refractory to this stimulation, since the DNA is not marked by RPA34 and prereplication complex protein might be inactivated (see below). This model accommodates the postulated licensing factor as well as the $S$ phase-specific DNA replication activator, in the form of a binary control mechanism, with a marker (RPA34) identifying the DNA for replication and a triggering complex (cyclin A-cdk2) activating the origin. Furthermore, the factor marking the DNA does not have to be degraded after initiation of DNA replication, as in the original licensing factor model of Blow and Laskey (1988). It suffices that posttranslational modification (for instance, phosphorylation) hinders binding to the DNA and in this way prevents rereplication.

The model presented here obviously does not account for all possible regulatory mechanisms operating at the onset of S phase. Studies in Saccharomyces cerevisiae indicated that there might be additional proteins involved in the regulation of DNA replication. For example, the CDC46 protein is required for DNA replication and shows a cell cycle-dependent distribution (Hennessy et al., 1990), like the postulated licensing factor. We recently detected expression of a CDC46 homolog in mouse cells (M. C. C., H. L., and J. McDermott, unpublished data), suggesting that a similar regulation may exist in mammals. In addition to these postulated regulatory mechanisms and circuits, DNA replication is most likely controlled by posttranslational modification of other replication proteins. DNA li- 
gase $\mathrm{I}$ is activated at the onset of $\mathrm{S}$ phase (Prigent et al., 1992), while DNA polymerase $\alpha$ is inactivated at the end of S phase (Nasheuer et al., 1991) by phosphorylation events. Furthermore, topoisomerase II is activated by phosphorylation in $\mathrm{M}$ phase (Ackerman et al., 1988; Saijo et al., 1990). Moreover, other types of modification might also be involved, e.g., the poly(ADP-ribosyl)ation of RPA70 (Eki and Hurwitz, 1991). Whatever the final picture may look like, it will embody a complex multitiered regulatory network, mediated by multiple factors at multiple levels, which all work together to ensure that DNA is coordinately replicated once and only once per cell cycle.

\section{Experimental Procedures}

\section{Cell Lines and Culture Conditions}

Mouse C2 skeletal muscle cells (Yaffe and Saxel, 1977) were cultured at $37^{\circ} \mathrm{C}$ in Dulbecco's modified Eagle's medium supplemented with $20 \%$ fetal calf serum (growth medium, GM). C2SVTts cells (Endo and Nadal-Ginard, 1989) were derived from this C2 cell line by stable trans fection of the SV40 tsA58 gene (Tegtmeyer and Ozer, 1971), coding for thermosensitive large $T$ and wild-type small $t$ fused to the mouse metallothionein I gene promoter. Mouse Swiss 3T3 fibroblast cells were grown at $37^{\circ} \mathrm{C}$ in Dulbecco's modified Eagle's medium supplemented with $10 \%$ fetal calf serum.

For immunofluorescence microscopy, cells were seeded onto gelatin-coated glass coverslips at a density of $3 \times 10^{3}$ cells per $\mathrm{cm}^{2}$ and allowed to attach in mitogen-rich medium (GM). Myogenic differentiation was induced by changing the cells to Dulbecco's modified Eagle's medium containing $5 \%$ horse serum (differentiation medium) and incubating at $39^{\circ} \mathrm{C}$ for $4-5$ days. Expression of $T$ antigen in these fully differentiated C2SVTts myotubes was achieved by shifting the cells to $\mathrm{GM}$ plus $\mathrm{Zn}^{2+}(0.1 \mathrm{mM})$ and incubating at $33^{\circ} \mathrm{C}$ for 1 day before fixation and immunostaining.

DNA synthesis was monitored by pulse labeling the cultures 5-10 min prior to fixation or throughout the induction period (continuous labeling) with the thymidine analog 5-bromo-2'-deoxyuridine (BrdU, $0.1 \mathrm{mM}$; Sigma).

\section{Immunofluorescence Microscopy}

Unless otherwise specified, all solutions were prepared in phosphatebuffered saline with $1.5 \mathrm{mM} \mathrm{MgCl}$ and $1 \mathrm{mM} \mathrm{CaCl}_{2}$ (hereafter referred to simply as PBS), all manipulations were at room temperature, and all dilutions were prepared in $3 \%$ bovine serum album in in PBS. Cells were washed once with PBS and either fixed for $10 \mathrm{~min}$ in $3.7 \%$ formalin in PBS, fixed for $2 \mathrm{~min}$ in $-20^{\circ} \mathrm{C}$ methanol, or first permeabilized for $30 \mathrm{~s}$ with Triton X-100 in CSK buffer ( $100 \mathrm{mM} \mathrm{NaCl}, 300 \mathrm{mM}$ sucrose, $3 \mathrm{mM} \mathrm{MgCl}_{2}, 10 \mathrm{mM}$ PIPES [pH 6.8]; Fey et al., 1986) and then fixed. Formalin-fixed cells were subsequently quenched for $10 \mathrm{~min}$ in $50 \mathrm{mM}$ glycine and permeabilized with $0.25 \%$ Triton X-100 in PBS for $10 \mathrm{~min}$. After blocking for $10 \mathrm{~min}$ in $3 \%$ bovine serum albumin in PBS, cells were incubated for $60 \mathrm{~min}$ with primary antibodies. After extensive washes with $0.1 \%$ Nonidet P-40 in PBS, cells were incubated for 60 min with secondary antibodies. These included fluorescein-conjugated goat anti-mouse immunoglobulin $\mathrm{G}$ (Boehringer Mannheim), biotinylated goat anti-mouse immunoglobulin $\mathrm{G}$, and biotinylated donkey anti-rabbit immunoglobulins (Amersham). The biotinylated antibodies were followed by incubation for $\mathbf{3 0} \mathrm{min}$ with streptavidin-Texas red (Amersham). Hoechst 33258 (Boehringer Mannheim) was used at a final concentration of $1 \mu \mathrm{g} / \mathrm{ml}$ in the last washes. Cells were mounted on glass slides with glycerol containing $50 \mu \mathrm{g} / \mathrm{ml}$ n-propyl gallate.

For visualization of BrdU incorporation, two methods were used. In one, the BrdU incorporated at sites of DNA replication was made accessible to the antibodies by treatment with nucleases, while the second procedure relied on acid denaturation of the DNA. In the former, cells were simultaneously stained with other primary (rabbit) antibodies diluted in a cocktail of anti-Brod monoclonal antibody with nucleases (Amersham), followed by secondary antibody incubations. In the latter, cells were first stained with a primary (rabbit or mouse) antibody followed by the Texas red detection system as above and sequentially fixed again, incubated for $10 \mathrm{~min}$ in $4 \mathrm{M}$ hydrochloric acid, washed $10 \mathrm{~min}$ with PBS, and finally directly stained with fluoresceinconjugated anti-BrdU monoclonal antibody (Boehringer Mannheim) for $60 \mathrm{~min}$.

Specimens were examined and photographed on a Zeiss Axiophot microscope equipped with phase contrast and epifluorescence optics, using $20 \times, 40 \times, 63 \times$, and $100 \times$ plan-apochromat and plan-neofluor lenses. Pictures were recorded on Kodak Ektar 25 and 100 films. Optical sections were obtained using the Bio-Rad MRC- 600 confocal imaging system. Micrographs were taken on Kodak Tmax 400 film.

\section{Antibodies}

The following primary antibodies were used: against cyclin A, affinitypurified rabbit anti-cyclin $A$ antibody (Girard et al., 1991) and two different rabbit anti-cyclin A antisera (Pines and Hunter, 1990; Pagano et al., 1992b); against cyclin B1, rabbit anti-cyclin B1 antiserum (Pines and Hunter, 1989); against cdk2, two different rabbit anti-cdk2 antisera raised against nonconserved C-terminal peptides (Tsai et al., 1993; Pagano ot al., 1992b); against cdc2, affinity-purified rabbit antibody to C-terminal peptide (Oncogene Science); against large T antigen, mouse monoclonal Pab101 (American Type Culture Collection); against PCNA, mouse monoclonal Z049 (Zymed); against BrdU, two different mouse monoclonals (Boehringer Mannheim and Amersham); against RPA34, mouse monocional aSSB-34A (Kenny et al., 1990); against RPA70, three different mouse monoclonal antibodies, aSSB70A, $\alpha$ SSB-70B, and $\alpha$ SSB-70C (Kenny et al., 1990)

\section{Acknowledgments}

We thank J. Hurwitz, M. Kenny, N. Lamb, M. Pagano, J. Pines, and L.-H. Tsai for antibodies and J. Galceran for help with the confocal microscope. We are indebted to $\mathrm{M}$. Pagano and $\mathrm{J}$. McDermott for comments on the manuscript and to R. Fotedar and M. Kenny for helpful discussions. H. L. received a postdoctoral fellowship from the Deutsche Forschungsgemeinschaft. This work was supported by grants from the National Institutes of Health.

Received April 14, 1993; revised July 9, 1993.

\section{References}

Ackerman, P., Glover, C. V. C., and Osheroff, N. (1988). Phosphorylation of DNA topoisomerase II in vivo and in total homogenates of Drosophila Kc cells. J. Biol. Chem. 263, 12653-12660.

Adachi, Y., and Laemmli, U. K. (1992). Identification of nuclear prereplication centers for DNA synthesis in Xenopus egg extracts: immunolocalization study of replication protein A. J. Cell Biol. 119, 1-15. Baldin, V., Lukás, J., Marcote, M. J., Pagano, M., and Draetla, G. (1993). Cyclin D1 is a nuclear protein required for cell cycle progression in G1. Genes Dev., in press.

Blau, H. M. (1992). Differentiation requires continuous active control. Annu. Rev. Biochem. 61, 1213-1230.

Blow, J. J., and Laskey, R. A. (1988). A role for the nuclear envelope in controlling DNA replication within the cell cycle. Nature 332, 546548.

Blow, J. J., and Watson, J. V. (1987). Nuclei act as independent and integrated units of replication in a Xenopus cell-free DNA replication system. EMBO J. 6, 1997-2002.

Bravo, R., and Macdonald-Bravo, H. (1987). Existence of two populations of cyclin/proliferating cell nuclear antigen during the cell cycle: association with DNA replication sites. J. Cell Biol. 105, 1549-1554. Bravo, R., Frank, R., Blundell, P. A., and Macdonald-Bravo, H. (1987). Cyclin/PCNA is the auxiliary protein of DNA polymerase- $\delta$. Nature 326, 515-517.

Calza, R. E., Eckhardt, L. A., DelGiudice, T., and Schildkraut, C. L. (1984). Changes in gene position are accompanied by a change in time of replication. Celt 36, 689-696.

Carter, K. C., Taneja, K. L., and Lawrence, J. B. (1991). Discrete nuclear domains of poly(A) RNA and their relationship to the functional organization of the nucleus. J. Cell Biol. 115, 1191-1202. 
Carter, K. C., Bowman, D., Carrington, W., Fogarty, K., McNeil, J. A. Fay, F. S., and Lawrence, J. B. (1993). A three dimensional view of precursor messenger RNA metabolism within the mammalian nucleus. Science 259, 1330-1335.

Cook, P. R. (1991). The nucleoskeleton and the topology of replication. Cell 66, 627-635.

D'Andrea, A. D., Tantravahi, U., LaLande, M., Perle, M. A., and Latt, S. A. (1983). High resolution analysis of the timing of replication of specific DNA sequences during $\mathbf{S}$ phase of mammalian cells. Nucl. Acids Res. 11, 4753-4774.

Dhar, V., Skoultchi, A. I., and Schildkraut, C. L. (1989). Activation and repression of a $\beta$-globin gene in cell hybrids is accompanied by a shift in its temporal replication. Mol. Cell. Biol. 9, 3524-3532.

Din, S.-U., Brill, S. J., Fairman, M. P., and Stillman, B. (1990). Cell cycle-regulated phosphorylation of DNA replication factor-A from human and yeast cells. Genes Dev. 4, 968-977.

D'Urso, G., Marracino, R. L., Marshak, D. R., and Roberts, J. M. (1990). Cell cycle control of DNA replication by a homologue from human cells of the p34 ${ }^{\mathrm{coc}}$ protein kinase. Science $250,786-791$.

Dutta, A., and Stillman, B. (1992). Cdc2 family kinases phosphorylate a human cell DNA replication factor, RPA, and activate DNA replication. EMBO J. 11, 2189-2199.

Dutta, A., Din, S., Brill, S. J., and Stillman, B. (1991). Phosphorylation of replication protein $A$ : a role for $\mathrm{Cd} / 2$ kinase in $\mathrm{G1} / \mathrm{S}$ regulation. Cold Spring Harbor Symp. Quant. Biol. 56, 315-324.

Eki, T., and Hurwitz, J. (1991). Influence of poly(ADP-ribose) polymerase on the enzymatic synthesis of SV40 DNA. J. Biol. Chem. 266 , 3087-3100.

Elledge, S. J., Richman, R., Hall, F. L., Williams, R. T., Lodgsom, N., and Harper, J. W. (1992). Cdk2 encodes a 33-kDa cyclin A-associated protein kinase and is expressed before cdc2 in the cell cycle. Proc. Natl. Acad. Sci. USA 89, 2907-2911.

Endo, T., and Nadal-Ginard, B. (1989). SV40 large T-antigen induces reentry of terminally differentiated myotubes into the cell cycle. In The Cellular and Molecular Biology of Muscle Development, L. H. Kedes and F. E. Stockdale, eds. (New York: Alan R. Liss), pp. 95-104.

Erdile, L. F., Wold, M. S., and Kelly, T. J. (1990). The primary structure of the 32-kDa subunit of human replication protein A. J. Biol. Chem. 265, 3177-3182.

Erdile, L. F., Heyers, W.-D., Kolodner, R., and Kelly, T. J. (1991). Characterization of a cDNA encoding the 70-kDa single-stranded DNAbinding subunit of human replication protein $A$ and the role of the protein in DNA replication. J. Biol. Chem. 266, 12090-12098.

Fang, F., and Newport, J.W. (1991). Evidence that the G1-S and the G2-M transitions are controlled by different cdc2 proteins in higher eukaryotes. Cell 66, 731-742.

Fey, E. G., Ornelles, D. A., and Penman, S. (1986). Association of RNA with the cytoskeleton and the nuclear matrix. J. Cell Sci. (Suppl.) 5, 99-119.

Fotedar, R., and Roberts, J. M. (1991). Association of p34 cdc2 with replicating DNA. Cold Spring Harbor Symp. Quant. Biol. 56, 325-333. Fotedar, R., and Roberts, J. M. (1992). Cell cycle regulated phosphorylation of RPA-32 occurs within the replication initiation complex. EMBO J. 11, 2177-2187.

Fox, M. H., Arndt-Jovin, D. J., Jovin, T. M., Baumann, P. H., and Robert-Nicoud, M. (1991). Spatial and temporal distribution of DNA replication sites localized by immunofluorescence and confocal microscopy in mouse fibroblasts. J. Cell Sci. 99, 247-253.

Gallant, P., and Nigg, E. A. (1992). Cyclin B2 undergoes cell cycledependent nuclear translocation and, when expressed as a nondestructible mutant, causes mitotic arrest in HeLa cells. J. Cell Biol. 777, 213-224.

Girard, F., Strausfeld, U., Fernandez, A., and Lamb, N. J. C. (1991). Cyclin $A$ is required for the onset of DNA replication in mammalian fibroblasts. Cell 67, 1169-1179.

Goldman, M. A., Holmquist, G. P., Gray, M. C., Caston, L. A., and Nag, A. (1984). Replication timing of genes and middle repetitive sequences. Science 224, 686-692.
Gu, W., Schneider, J. W., Condorelli, G., Kaushal, S., Mahdavi, V., and Nadal-Ginard, B. (1993). Interaction of myogenic factors and the retinoblastoma protein mediates muscle cell commitment and differentiation. Cell 72, 309-324.

Hall, Z. W., and Ralston, E. (1989). Nuclear domains in muscle cells. Cell 59, 771-772.

Hamaguchi, J. R., Tobey, R. A., Pines, J., Crissman, H. A., Hunter, T., and Bradbury, E. M. (1992). Requirement for p34 ${ }^{\text {coce }}$ kinase is restricted to mitosis in the mammalian cdc2 mutant FT210. J. Cell Biol. 117, 1041-1053.

Hastings. K. E. N., and Emerson, C. P. (1984). Proliferation and gene regulation in skeletal muscle myogenesis: recombinant DNA approaches. In Recombinant DNA and Cell Proliferation, G. S. Stein and J. L. Stein, eds. (Orlando, Florida: Acedemic Press), pp. 219-241.

Hatton, K. S., Dhar, V., Brown, E. H., Iqbal, M. A., Stuart, S., Didamo, V. T., and Schildkraut, C. L. (1988). Replication program of active and inactive multigene families in mammalian cells. Mol. Cell. Biol. 8, 2149-2158

Hennessy, K. M., Clark, C. D., and Botstein, D. (1990). Subcellular localization of yeast $C D C 46$ varies with the cell cycle. Genes Dev. 4, 2252-2263.

Huang, S., and Spector, D. L. (1991). Nascent pre-mRNA transcripts are associated with nuclear regions enriched in splicing factors. Genes Dev. 5, 2288-2302.

Huberman, J. A., and Riggs, A. D. (1968). On the mechanism of DNA replication in mammalian chromosomes. J. Mol. Biol. 32, 327-337.

Kenny, M. K., Schlegel, U., Furneaux, H., and Hurwitz, J. (1990). The role of human single-stranded DNA binding protein and its individual subunits in simian virus DNA replication. J. Biol. Chem. 265, 76937700 .

Königsberg, I. R., McElvain, N., Tootle, M., and Herrman, H. (1960) The dissociability of deoxyribonucleic acid synthesis from the development of multinuclearity of muscle cells in culture. J. Biophys. Biochem. Cytol. 8, 333-343.

Kumar, A., and Warner, J. R. (1972). Characterization of ribosomal precursor particles from HeLa cell nucleoli. J. Mol. Biol. 63, 233-246. Laskey, R. A., Fairman, M. P., and Blow, J. J. (1989). S phase of the cell cycle. Science 246, 609-614

Lehner, C. F., Yakubovich, N., and O'Farrel, P. H. (1991). Exploring the role of Drosophila cyclin $\mathrm{A}$ in the regulation of $\mathrm{S}$ phase. Cold Spring Harbor Symp. Quant. Biol. 56, 465-475.

Leno, G. H., and Laskey, R. A. (1991). The nuclear membrane determines the timing of DNA replication in Xenopus egg extracts. J. Cell Biol. 112, 557-566.

Leonhardt, H., Page, A. W., Weier, H.-U., and Bestor, T. H. (1992). A targeting sequence directs DNA methyltransferase to sites of DNA replication in mammalian nuclei. Cell $71,865-873$.

Lew, D. J., and Reed, S. I. (1992). A proliferation of cyclins. Trends Cell Biol. 2, 77-81.

Mills, A. D., Blow, J. J., White, J. G., Amos, W. B., Wilcock, D., and Laskey, R. A. (1989). Replication occurs at discrete foci spaced throughout nuclei replicating in vitro. J. Cell Sci. 94, 471-477.

Moore, S. P., Erdile, L., Kelly, T., and Fishel, R. (1991). The human homologous pairing protein HPP-1 is specifically stimulated by the cognate single-stranded binding protein hRP-A. Proc. Natl. Acad. Sci. USA 88, 9067-9071.

Moser, F. G., Dorman, B. P., and Ruddle, F. H. (1975). Mouse-human heterokaryon analysis with a 33258 Hoechst-Giemsa technique. J. Cell Biol. 66. 676-680.

Nadal-Ginard, B. (1978). Commitment, fusion and biochemical differentiation of a myogenic cell line in the absence of DNA synthesis. Cell 15. 855-864.

Nakagawa, M., Tsukada, S., Soma, T., Shimizu, Y., Miyake, S., Iwamatsu, A., and Sugiyama, H. (1991). cDNA cloning of the murine 30 . $\mathrm{kDa}$ protein homologous to the $32-\mathrm{kDa}$ subunit of human replication protein A. Nucl. Acids Res. 19, 4292.

Nakamura, H., Morita, T., and Sato, C. (1986). Structural organization of replicon domains during DNA synthetic phase in the mammalian 
nucleus. Exp. Cell Res. 165, 291-297.

Nakayasu, H., and Berezney, R. (1989). Mapping replication sites in the eukaryotic cell nucleus. J. Cell Biol. 108, 1-11.

Nashever, H.-P., Moore, A., Wahl, A. F., and Wang, T. S.-F. (1991) Cell cycle-dependent phosphorylation of human DNA polymerase $\alpha$ J. Biol. Chem. 266, 7893-7903.

Nevins, J. R. (1992). E2F: a link between the Rb tumor suppressor protein and viral oncoproteins. Science 258, 424-429.

Ohtsubo, M., and Roberts, J. M. (1993). Cyclin-dependent regulation of $\mathrm{G} 1$ in mammalian fibroblasts. Science 259, 1908-1912.

O'Keefe, R. T., Henderson, S. C., and Spector, D. L. (1992). Dynamic organization of DNA replication in mammalian cell nuclei: spatially and temporally defined replication of chromosome-specific a-satellite DNA sequences. J. Cell. Biol. 116, 1095-1110.

Pagano, M., Draetta, G., and Jansen-Dürr, P. (1992a). Association of cdk2 kinase with the transcription factor E2F during $S$ phase. Science 255, 1144-1147.

Pagano, M., Pepperkok, R., Verde, F., Ansorge, W., and Draetta, G. (1992b). Cyclin A is required at two points in the human cell cycle. EMBO J. 11, 961-971.

Pagano, M., Pepperkok, R., Lukás, J., Baldin, V., Ansorge, W., Bartek, J., and Draetta, G. (1993). Regulation of the cell cycle by the cdk? protein kinase in cultured human fibroblasts. J. Cell Biol. 121, 101111.

Pines, J., and Hunter, T. (1989). Isolation of a human cyclin cDNA: evidence for cyclin mRNA and protein regulation in the cell cycle and for interaction with p34 ${ }^{\text {coce }}$. Cell $58,833-846$.

Pines, J., and Hunter, T. (1990). Human cyclin A is adenovirus E1Aassociated protein p60 and behaves differently from cyclin B. Nature 346, 760-763.

Pines, J., and Hunter, T. (1991). Human cyclins A and B1 are differentially located in the cell and undergo cell cycle-dependent nuclear transport. J. Cell Biol. 115, 1-17.

Prelich, G., Tan, C.-K., Kostura, M., Mathews, M. B., So, A. G., Downey, K. M. and Stillman, B. (1987). Functional identity of proliferating cell nuclear antigen and a DNA polymerase- $\delta$ auxiliary protein. Nature 326, 517-520.

Prigent, C., Lasko, D. D., Kodama, K., Woodgett, J. R., and Lindahl, T. (1992). Activation of mammalian DNA ligase I through phosphorylation by casein kinase II. EMBO J. 11, 2925-2933.

Rao, P. N., and Johnson, R. T. (1970). Mammalian cell fusion: studies on the regulation of DNA synthesis and mitosis. Nature 225, 159-164. Ray, S., Anderson, M. E., Loeber, G., McVey, D., and Teglmeyer, P. (1992). Functional characterization of temperature-sensitive mutants of simian virus 40 large $\mathrm{T}$ antigen. J. Virol. 66, 6509-6516.

Reed, S. I. (1991). G1-specific cyclins: in search of the S-phasepromoting factor. Trends Genet. 7, 95-99.

Roberts, J. M., and D'Urso, G. (1988). An origin-unwinding activity regulates initiation of DNA replication during mammalian cell cycle. Science 241, 1486-1489.

Rosenblatt, J., Gu, Y., and Morgan, D. O. (1992). Human cyclindependent kinase 2 is activated during the $S$ and $G 2$ phases of the cell cycle and associates with cyclin A. Proc. Natl. Acad. Sci. USA 89, 2824-2828.

Saijo, M., Enomoto, T., Hanaoka, F., and Ui, M. (1990). Purification and characterization of type II DNA topoisomerase from mouse FM3A cells: phosphorylation of topoisomerase II and modification of its activity. Biochemistry 29, 583-590.

Spector, D. L., Fu, X.-D., and Maniatis, T. (1991). Associations between distinct pre-mRNA splicing components and the cell nucleus. EMBO J. 10, 3467-3481.

Stockdale, F. E., and Holtzer, H. (1961). DNA synthesis and myogenesis. Exp. Cell Res. 24, 508-520.

Tegtmeyer, P., and Ozer, H. L. (1971). Temperature sensitive mutants of simian virus 40: infection of permissive cells. J. Virol. 8, 516-524. Tsai, L.-H., Harlow, E., and Meyerson, M. (1991). Isolation of the human cdk2 gene that encodes the cyclin A- and E1A-associated p33 kinase. Nature $353,174-177$.
Tsai, L.-H., Lees, E., Faha, B., Harlow, E., and Riabowol, K. (1993). Cdk2 kinase is required for the $\mathrm{G} 1$ to $S$ transition in mammalian cells. Oncogene, in press.

van Dierendonck, J. H., Keyser, R., van de Velde, C. J. H., and Cornelisse, C. J. (1989). Subdivision of S-phase by analysis of nuclear 5-bromodeoxyuridine staining patterns. Cytometry 10, 143-150.

Wang, J., Cao, L.-G., Wang, Y.-L., and Pederson, T. (1991). Localization of pre-messenger RNA at discrete nuclear sites. Proc. Natl. Acad. Sci. USA 88, 7391-7395.

Weisblum, B., and Haenssler, E. (1974). Fluorometric properties of the bisbenzimidazole derivative Hoechst 33258, a fluorescent probe specific for AT concentration in chromosomal DNA. Chromosoma 46 , 255-260.

Xing, Y., Johnson, C. V., Dobner, P. R., and Lawrence, J. B. (1993). Higher level organization of individual gene transcription and RNA splicing. Science 259, 1326-1330.

Yaffe, D., and Saxel, O. (1977). Serial passaging and differentiation of myogenic cells isolated from dystrophic mouse muscle. Nature 270 , 725-727.

Zindy, F., Lamas, E., Chenivesse, X., Sobczak, J., Wang, J., Fesquet, D., Henglein, B., and Bréchot, C. (1992). Cyclin A is required in $S$ phase in normal epithelial cells. Biochem. Biophys. Res. Commun. 182, 1144-1154. 